\title{
Attempted suicide to be punished or not: professional opinion BN Raveesh
}

\author{
Address: Mental Informatics Treatment \& Research Academy, \#2955, 1st main, 2nd cross, Saraswathipuram, Mysore 570009, India \\ from WPA Thematic Conference. Coercive Treatment in Psychiatry: A Comprehensive Review \\ Dresden, Germany. 6-8 June 2007 \\ Published: 19 December 2007 \\ BMC Psychiatry 2007, 7(Suppl I):SII6 doi:I0.II86/I47I-244X-7-SI-SII6
}

This abstract is available from: http://www.biomedcentral.com/I47I-244X/7/SI/SI I6

(C) 2007 Raveesh; licensee BioMed Central Ltd.

\section{Background}

This study tried to find whether an attempted suicide is to be punished or not and to find out whether the law has been perceived as a preventer for attempting suicide.

\section{Methods}

This was a randomized experimental study. The sample (total 300) consisted of professionals from five different groups (60 in each group). They were doctors (non-mental health), mental health workers (including psychiatrists, psychologists and psychiatric social workers), advocates/lawyers, police officers (of different cadre) and engineers. The participants completed a questionnaire specially prepared for this purpose.

\section{Results}

With regard to awareness about laws on attempted suicide significant differences were found pertaining to age $(\mathrm{p}=$ $0.001)$, sex $(\mathrm{p}=0.05)$, qualification $(\mathrm{p}=0.017)$ and profession ( $p=0.001)$ of the study participants. No significant difference was found with regard to the opinion on punishing the suicide attempters that pertained to the age $(\mathrm{p}=0.232)$ and sex $(\mathrm{p}=0.510)$ of the study participants. However, qualification and profession showed significant differences. None of the participants held the opinion that the existing law on suicide is successful in deterring suicidal attempts for more than $50 \%$. Doctors $(76.7 \%)$, engineers $(93.3 \%)$ and mental health workers $(78.3 \%)$ particularly with postgraduate $(68.9 \%)$ qualification recommended abolishing the existing laws on suicide, which is not supported by lawyers and police officers.

\section{Conclusion}

An ethical, legal and clinical framework for decision making is essential to underpin robust management of sensitive human behavior like suicide. 